Article

\title{
Job satisfaction and caring behavior among nurses in a military hospital: A cross-sectional study
}

\author{
Kuswantoro Rusca Putra, Tutut Andayani, Evi Harwiati Ningrum \\ School of Nursing, Faculty of Medicine, Universitas Brawijaya, Malang, Indonesia
}

\begin{abstract}
Background: Caring is the major focus of nursing practice, and their behavior has an impact on the quality of patient care, and it is very important that they are satisfied while working. The strong relationship between job satisfaction and nurses caring behavior is well established, and therefore the managers can be encouraged to provide better conditions for nurses' satisfaction. The aim of this study was to investigate the relationship between job satisfaction and the caring behavior of nurses in the Military Hospital.

Design and Methods: A survey with a self-assessment questionnaire was carried out from August to December 2019. Participants were 121 nurses working in a military hospital Malang, Indonesia. The data was collected using the Job Satisfaction Survey (JSS) and Caring Behavior Inventory (CBI24). The data were analyzed using rank Spearman and multiple linear regression.

Results: Job satisfaction had a positive correlation with the caring behavior of nurses $(\mathrm{p}=0.003 ; \mathrm{r}=0.266)$. Furthermore, there were four job satisfaction dimensions namely supervision, contingent rewards, co-workers, nature of work and communication dimensions were positively correlated with nurses' caring behavior $(p<0.05)$ while salary, promotion, benefits, operating procedure dimensions are not related to nurse's caring behavior $(\mathrm{p}>0.05)$.

Conclusions: Caring behavior of nurses is influenced by job satisfaction. Therefore, it is necessary to provide supervision, contingent rewards, empowerment, collaboration program for the nurses to reconstruct the nursing working environment to be healthier and increase the caring behavior of nurses.
\end{abstract}

\section{Introduction}

Quality health care is the result of collaboration between patients and health care providers in a supportive environment. ${ }^{1}$ Nurses as professionals are responsible for the provision of high quality nursing care for better patient outcomes and every effort is made through their caring behavior. ${ }^{2}$ Furthermore, caring is an interpersonal process with a specific context characterized by excellent nursing skills, interpersonal responsiveness, and intimate relationships initiated by the nurse's need and openness to care, as well as professional maturity and willingness to nurture their moral foundation. ${ }^{3}$ In general, nurses perform sufficient patient care, however they often less attentive to caring behavior aspects. ${ }^{4}$ Another studies showed that nurses are more focused on the application of skills or carrying out a task than on existing caring behaviors that demonstrate compassion, love, kindness, and relationships. ${ }^{5}$ Their work performance appearance is influenced by job satisfaction. ${ }^{6-8}$

Nurses believe that the quality of care provided by their work unit has a strong impact on job satisfaction, and believe that their work unit provides excellent quality of care that also provides the highest level of satisfaction. ${ }^{9}$ Job satisfaction is a pleasant feeling or assessing the expression of positive emotion to an individual's work or working experience. ${ }^{10}$ Interpersonal relationships in the working place are providing good patient care, physical working conditions, salary, promotion, job security, responsibilities, working hours, management, staffing and resources, which are predictors of job satisfaction. ${ }^{11,12}$ There was no difference in overall satisfaction between military $v s$ civilian services, professional $v s$ non-professional nurses, general $v s$ specialized care in military hospitals. ${ }^{6,13}$ The four most preferred responses were staff interaction, patient care, unit or specialization, learning environment, while the least preferred were the hospital's military/political structure, staff shortages, schedules, and unsupportive administration. ${ }^{6}$ Based on the results above, this study aims to examine the relationship between Nurses' job satisfaction and caring behavior who work in the Military Hospital.

\section{Design and Methods}

The research uses a descriptive quantitative design with a cross-sectional approach and random sampling. Overall respondents involved in this study were 121 nurses working in the inpatient wards at the Military Hospital in Malang, East Java. The instrument used in measuring the job satisfaction was the Job Satisfaction Survey (JSS), which consists of 36 items, divided into 9 sub-dimensions, namely: salary (4 item), promotion (4 item), fringe benefits (4 item), contingent rewards (4 item), supervision (4 item), operation procedure (4 item), Co-worker (4 item), nature of work (4 item), and communication (4 item). This instrument uses a 6 -point Likert scale $(1=$ disagree very much, $2=$ disagree moderately, $3=$ disagree slightly, 4=agree slightly, $5=$ agree moder-

Significance for public health

The nurses are group of health-care professionals that have the largest number of healthcare workforce in the world. Nurses practice independently and have the ability in promoting and maintaining human health. However, their job satisfaction is rarely investigated, and there are several negative impacts that may arise from unsatisfied nurses. The decreased motivation in providing care, leading to an increase in patient complaints as well as potential safety incidence. These consequences indicated a red flag for the qualified healthcare services provided in the public health. This study examines the relationship between job satisfaction and the caring behavior of nurses. The result is expected to identify specific factors of job satisfaction that can be modified to maintain caring behavior in which the decreasing quality of care can be prevented. 
ately, $6=$ agree very much). The instrument used for measuring caring behavior was Caring Behavior Inventory (CBI-24). ${ }^{15}$ This instrument consists of 24 items, divided into 4 sub-scale, assurance (8 item), knowledge and skill (5 item), respectful (5 item) and connectedness ( 5 item). 6-point Likert scale $(1=$ never, $2=$ almost never, $3=$ occasionally, $4=$ usually, 5=almost always, 6=always). The instrument was tested for validity and reliability with the results of all valid question items $(r>0.45)$ and Cronbach Alpha value (0.907) for JSS and (0.954) for CBI-24. This research was conducted after obtaining ethical clearance from the Health Research Ethics Commission of the Faculty of Medicine, Universitas Brawijaya, Indonesia. All respondents participated had previously received informed consent. Participants fully understand the concept of the research and agreed to respond to the questionnaire. The entire survey process used anonymity and all personal information was kept confidential. The data collection was carried out by using paper-based questionnaire, which was distributed to nurses at the inpatient wards. All the eligible nurses were given informed consent prior to the survey distribution, and the consent were earned when nurses signed the informed consent form and completed the survey. In terms of statistical analysis, the frequency distribution was used to perform a univariate analysis in the characteristics of the respondents. While job satisfaction and caring behavior were examined using descriptive statistic. The Spearman rank test were used to examine the relationship between job satisfaction and car-

Table 1. Characteristics of respondents based on gender, age, education and experience $(n=121)$.

\begin{tabular}{lcc} 
Characteristics of respondents & Frequency & Percentage \\
Gender & & \\
$\quad$ Female & 32 & $26.4 \%$ \\
$\quad$ Male & 89 & $73.6 \%$ \\
Age & & \\
$\quad 20-30$ & 53 & $43.8 \%$ \\
$\quad 31-40$ & 50 & $41.3 \%$ \\
$\quad>40$ & 18 & $14.9 \%$ \\
\hline Education & & \\
$\quad$ Diploma & 92 & $76 \%$ \\
$\quad$ Bachelor & 29 & $24 \%$ \\
Experiences (year) & & \\
$\quad 55$ & 48 & $39.7 \%$ \\
$\quad>5$ & 73 & $60.3 \%$ \\
\hline
\end{tabular}

Table 2. Distribution of variables job satisfaction (salary, promotion, fringe benefits, contingent rewards, supervision, operation procedure, co-worker, nature of work, communication) and caring behavior $(n=121)$.

\begin{tabular}{lccccc} 
Variables & Mean & Median & Min-Max & SD & $95 \%$ CI \\
Job satisfaction (total) & 4.01 & 3.88 & $3.17-4.83$ & 0.45 & $3.93-4.09$ \\
Salary & 3.77 & 3.75 & $2.00-5.25$ & 0.73 & $3.64-3.90$ \\
\hline Promotion & 3.73 & 3.75 & $2.25-5.00$ & 0.56 & $3.63-3.83$ \\
Fringe benefits & 3.63 & 3.50 & $2.00-4.75$ & 0.52 & $3.53-3.72$ \\
\hline Contingent rewards & 3.83 & 3.75 & $2.50-5.00$ & 0.66 & $3.71-3.95$ \\
Supervision & 4.34 & 4.25 & $2.50-6.00$ & 0.77 & $4.20-4.48$ \\
\hline Operation procedure & 3.16 & 3.25 & $2.00-5.00$ & 0.52 & $3.06-3.25$ \\
Co-worker & 4.76 & 5.00 & $3.50-5.75$ & 0.67 & $4.64-4.88$ \\
\hline Nature of work & 4.87 & 4.75 & $3.50-5.75$ & 0.53 & $4.77-4.96$ \\
Communication & 4.03 & 3.75 & $1.50-6.00$ & 0.97 & $3.85-4.20$ \\
\hline Caring behavior & 5.16 & 5.08 & $4.21-5.75$ & 0.39 & $4.21-5.75$ \\
\hline
\end{tabular}

SD, standard deviation; Min, minimal; Max, maximal; CI, confidence interval. ing behavior. In addition, the correlation of ten domains of job satisfaction to nurses' caring behavior were also closely examined using multivariate linear regression model was examine and all the statistical analysis was performed using SPSS 16.

\section{Results and Discussions}

The respondents' characteristic data includes gender, age, education, and experience as described in Table 1, which shows that the majority of respondents were male $(73.6 \%)$, age $<40$ years $(85.1 \%)$, education diploma $(75 \%)$, and experience $>5$ year $(60.3 \%)$. Based on Table 2, it can be predicted using 95\% confidence interval total score of job satisfaction score ranges from 3.93-4.09 (salary score was between 3.64-3.90; promotion scores between 3.63-3.83; fringe benefits scores between 3.53-3.72; contingent rewards scores between 3.71-3.95; supervision of the scores were between 4.20-4.48; operation procedure scores between 3.06-3.25; co-worker scores between 4.64-4.88; nature of work scores between 4.77-4.96; communication scores between 3.85 4.20), while the caring behavior scores ranged from 4.215.75. The relationship between total score of job satisfaction and its dimensions (salary, promotion, fringe benefits, contingent rewards, supervision, operation procedure, co-worker, nature of work, communication) and caring behavior can be seen in Table 3 . The score of the total job satisfaction has a relationship with caring behavior $(p<0.05)$. Sub variable job satisfaction (contingent rewards, supervision, co-worker, nature of work, and communication) has a relationship with caring behavior $(\mathrm{p}<0.05)$.

Table 3. Analysis of the relationship between variables total score job satisfaction (salary, promotion, fringe benefits, contingent rewards, supervision, operation procedure, co-worker, nature of work, communication) and caring behavior variables $(n=121)$.

\begin{tabular}{lcc} 
Variable & Correlation coefficient & p-value \\
Job satisfaction (total) & 0.26 & 0.003 \\
Salary & 0.02 & 0.824 \\
\hline Promotion & -0.12 & 0.185 \\
Fringe benefits & -0.01 & 0.871 \\
\hline Contingent rewards & 0.21 & 0.019 \\
Supervision & 0.34 & 0.000 \\
\hline Operation procedure & 0.02 & 0.826 \\
Co-worker & 0.24 & 0.006 \\
\hline Nature of work & 0.35 & 0.000 \\
Communication & 0.25 & 0.000 \\
\hline
\end{tabular}

Table 4. Multiple linear regression analysis.

Independent variable B $t$-value p-value Adjusted R square

\begin{tabular}{lcccc} 
Constant & 4.930 & & & 0.201 \\
Salary & -.184 & -2.281 & 0.024 & \\
\hline Promotion & -.037 & -.517 & 0.606 & \\
Fringe benefits & .013 & .143 & 0.887 \\
\hline Contingent rewards & -.159 & -2.107 & 0.037 \\
Supervision & .196 & 2.322 & 0.022 \\
\hline Operation procedure & -.101 & -1.333 & 0.185 \\
Co-worker & -.071 & -1.032 & 0.304 \\
\hline Nature of work & .135 & 1.616 & 0.109 \\
Communication & .190 & 3.028 & 0.003
\end{tabular}


From the performed multiple linear regression analysis, four job satisfaction dimensions (salary, contingent rewards, supervision, and communication) are greatly associated with nurses' caring behavior (Table 4). The results of the multicollinearity assumption test (tolerance value $>0.27$ and VIF $<4.4$ ), autocorrelation (Durbin Watson=1.468), normality (probability plot, residual observations spread around the diagonal line), heteroscedasticity (scatter plot, randomly spread residual observations), showed that multiple linear regression analysis can be performed. The results of multiple linear regression analysis showed that only the salary, contingent rewards, supervision and communication affect nurses' caring behavior. The caring behavior of the nurses can be represented by salary, contingent rewards, supervision, and communication by $20.1 \%$, or in other words it contributed about $21.1 \%$ to the caring behavior of the nurses, while the remaining $79.9 \%$ is a contribution from other factors that are not in the model linear regression. Caring is at the core of nursing and the nurse caring behavior is a service provided to the patients. ${ }^{14}$ Nurse job satisfaction is very important in providing high quality service to patients. ${ }^{1}$ Nurse's job satisfaction can be measured in terms of salary, promotion, supervision, benefits, contingent reward, operating procedures, coworkers, nature of work, and communication. ${ }^{15}$ This research shows that nurses' job satisfaction are positively related to their caring behavior. This study is in line with the results of several studies, which reported that nurse caring behavior is influenced by job satisfaction. ${ }^{2,16,17}$ Other studies suggest that job satisfaction can improve the performance of nurses and the quality of patient care. ${ }^{9,18-20}$

In this study, the salary and reward nurses receive is known to have an impact on the nurses' behavior. Salary is recognized as the main reason for increased efforts to improve the quality of care and nurses. ${ }^{7,21}$ Nurses prefer non-financial rewards, including community appreciation and feedback, time and working management, job content and development opportunities, influencing and participation are closely related to the importance of rewards. ${ }^{22}$ The direction in this study is negative, meaning that the greater the salary received by nurses, the lower the nurses' caring behavior. This condition is suspected because most of the respondents have worked for more than five years, in such a way that the salary and rewards is quite stable.

Supervision is one of the influencing factors to nurses' performance, such as the caring behavior. The better the supervision carried out at the hospital, the better the nurse's performance. These results are similar with previous study finding that supervision has an effect on nurses' performance. ${ }^{8,23,24}$ Clinical supervision has significant impact on self-assurance improvement, an increased nurse supportive behavior to their patients, relationship with the patient, and taking responsibility. ${ }^{25}$

Communication is a factor that has the greatest influence on nurse caring behavior, the better communication performed by nurse, the better nurse's caring behavior. Good communication will improve the quality of nursing care delivered to patients. ${ }^{26,27}$ The communication skills possessed by nurses affects their caring behavior in providing nursing care to patients. ${ }^{28}$

\section{Conclusions}

Nurses' caring behavior is very important for high quality health services, in such a way that the hospital management must implement a program to improve the nurses' ability and skills. Nurse satisfaction needs to be managed properly in order to improve their performance, especially the implementation of caring in nursing services. Financial rewards are important, but nonfinancial rewards are also very important to be managed by hospi- tal management. Another very important factor to consider is the management of the communication skills in caring behavior in providing nursing care for patients and their families.

Correspondence: Kuswantoro Rusca Putra, School of Nursing, Faculty of Medicine, Universitas Brawijaya, Jl. Puncak Dieng, Kunci, Kalisongo, Kec. Dau, Malang, East Java 65151, Indonesia. Tel. +62.341569117 - Fax: +62.341564755. E-mail: torro.fk@ub.ac.id

Key words: Caring behavior; job satisfaction; military hospital; nurses; quality.

Acknowledgment: The author expresses profound gratitude to the Military Hospital in Malang for all the support and opportunity during this study and the active participation of all nurses.

Contributions: KRP contributed to the design and implementation of the study, to the analysis of the results; TA assisted with the technical details and implementation of the study; KRP and EHN wrote the manuscript with input from all authors.

Conflict of Interests: The author declares that there was no conflict of interest in this study.

Funding: This study was independently funded by the authors.

Ethics approval: This study has been approved by Health Research Ethics Committee of Faculty of Medicine, Universitas Brawijaya, Malang, Indonesia (n. 253/EC/KEPK-S1-PSIK/09/2019).

Conference presentation: Part of this study was presented at the $1^{\text {st }}$ International Nursing and Health Sciences Symposium, November $13^{\text {th }}$ to $15^{\text {th }} 2020$, Brawijaya University, Malang, Indonesia.

Received for publication: 16 January 2021

Accepted for publication: 20 March 2021.

oCopyright: the Author(s), 2021

Licensee PAGEPress, Italy

Journal of Public Health Research 2021;10:2212

doi:10.4081/jphr.2021.2212

This work is licensed under a Creative Commons Attribution NonCommercial 4.0 License (CC BY-NC 4.0).

\section{References}

1. Mosadeghrad AM. Factors influencing healthcare service quality. Int J Heal Policy Manag 2014;3:77-89.

2. Oluma A, Abadiga M. Caring behavior and associated factors among nurses working in Jimma University specialized hospital, Oromia, Southwest Ethiopia, 2019. BMC Nurs 2020;19:17.

3. Finfgeld-Connett D. Meta-synthesis of caring in nursing. J Clin Nurs 2008;17:196-204.

4. Yau XC, Tam WSW, Seah HWV, et al. An exploration of factors influencing inpatient nurses' care behaviour in an acute hospital setting. Int J Qual Heal Care 2019;31:473-9.

5. Vujanić J, Prlić N, Lovrić R. Nurses' self-assessment of caring behaviors in nurse-patient interactions: A cross-sectional study. Int J Environ Res Public Health 2020;17:1-15.

6. Allgood C, O'Rourke K, VanDerslice J, Hardy MA. Job satisfaction among nursing staff in a military health care facility. Mil Med 2000;165:757-61. 
7. Ali M, Qun W. Factors contributing job satisfaction and job performance of nurses in the healthcare industry. Int J Humanit Soc Dev Res 2019;3:7-22.

8. Doloh N, Tamtomo D, Sulaeman ES. Factors affecting work performance among nurses in delivering health service for the national health insurance patients at Dr. Moewardi Hospital, Surakarta. J Heal Policy Manag 2018;3:20-25.

9. Kvist T, Mäntynen R, Partanen P, et al. The job satisfaction of Finnish nursing staff: The development of a job satisfaction scale and survey results. Nurs Res Pract 2012;2012:1-11.

10. Lambrou P, Kontodimopoulos N, Niakas D. Motivation and job satisfaction among medical and nursing staff in a Cyprus public general hospital. Hum Resour Health 2010;8:1-9.

11. Choi SPP, Cheung K, Pang SMC. Attributes of nursing work environment as predictors of registered nurses' job satisfaction and intention to leave. J Nurs Manag 2013;21:429-39.

12. van der Doef M, Mbazzi FB, Verhoeven C. Job conditions, job satisfaction, somatic complaints and burnout among East African nurses. J Clin Nurs 2012;21:1763-75.

13. Zangaro GA, Johantgen M. Registered nurses' job satisfaction in navy hospitals. Mil Med 2009;174:76-81.

14. Shalaby SA, Janbi NF, Mohammed KK, et al. Assessing the caring behaviors of critical care nurses. J Nurs Educ Pract 2018;8:77.

15. Spector PE. Measurement of human service staff satisfaction: Development of the job satisfaction survey. Am J Community Psychol 1985;13:693-713.

16. Amelework N, Sisay G. Factors associated with nurses perception about nurse caring behaviors (case at hospitals of Harar Town, Eastern Ethiopia). Int J Heal Nursing Med 2019;1:21-9.

17. Xerri MJ. Examining the relationship between organisational justice, job satisfaction and the innovative behaviour of nursing employees. Int J Innov Manag 2014;18:1-22.
18. Dekoulou P, Trivellas P. Measuring the impact of learning organization on job satisfaction and individual performance in Greek advertising sector. Procedia Soc Behav Sci 2015; 175:367-75.

19. Abbas A. Impact of job satisfaction on job performance of nurses at Al-Suwaira. Iraqi Natl J Nurs Spec 2017;30:73-82.

20. Rudasingwa M, Uwizeye MR. Physicians' and nurses' attitudes towards performance-based financial incentives in Burundi: A qualitative study in the province of Gitega. Glob Health Action 2017;10:1-15.

21. Seitovirta J, Lehtimäki AV, Vehviläinen-Julkunen $\mathrm{K}$, et al. Registered nurses' perceptions of rewarding and its significance. J Nurs Manag 2018;26:457-66.

22. Snowdon DA, Leggat SG, Taylor NF. Does clinical supervision of healthcare professionals improve effectiveness of care and patient experience? A systematic review. BMC Health Serv Res 2017; 17:1-11.

23. Mohammadi F, Nikan A, Movasagh F, et al. The effect of clinical supervision on clinical decision. Int $\mathrm{J}$ Pharm Res 2019;11:1761-5.

24. Berggren I, Severinsson E. The influence of clinical supervision on nurses' moral decision making. Nurs Ethics 2000;7:124-33.

25. Khodadadi E, Ebrahimi H, Moghaddasian S, et al. The effect of communication skills training on quality of care, self-efficacy, job satisfaction and communication skills rate of nurses in hospitals of Tabriz, Iran. J Caring Sci 2013;2:27-37.

26. Vermeir P, Vandijck D, Degroote S, et al. Communication in healthcare: A narrative review of the literature and practical recommendations. Int J Clin Pract 2015;69:1257-67.

27. Kirca N, Bademli K. Relationship between communication skills and care behaviors of nurses. Perspect Psychiatr Care 2019;55:624-31. 